\title{
Program Surveillance After Breast Cancer Treatment: Much Needed, but Still not Ready for Clinical Practice?
}

\author{
Wolfgang Janni \\ Frauenklinik Innenstadt, Klinikum der Ludwig-Maximilians-Universität, München, Germany
}

One of the most frequently asked questions from patients after the completion of primary treatment for early breast cancer is whether the treatment was successful after all. Due to the lack of adequate monitoring tools, doctors are not only without a reliable basis for answering this question at the time of primary treatment, but have to face the same insecurity as the patient herself for the coming years of follow-up. Therefore, both patients and doctors are in desperate need for better monitoring tools for the follow-up of breast cancer patients than are currently available.

In their editorial, Siegfried Seeber and Anja Welt [1] point out that the evidence for not including tumor markers and imaging diagnostics (with the exception of mammography) into the routine of routine follow-up is far from solid and beyond doubt. They convincingly argue that the design of the two Italian randomized trials was not optimal and that novel and successful treatment options for metastatic breast cancer were not available during the 1980s, when these studies were performed. The authors conclude that the lack of benefit from intensified surveillance that was demonstrated more than 20 years ago cannot be a sufficient reason for denying intensified surveillance and early detection of metastatic disease nowadays. They picture scenarios in which the early detection and treatment of oligometastatic disease might lead to long-term remission.

Jennifer Griggs and Daniel Hayes [2], on the other hand, stress the fact that early detection of asymptomatic metastatic disease has never been shown to lead to a higher likelihood of cure. They acknowledge the lack of data and the patients' desire for intensive surveillance but argue that the resources should be better used for optimal adjuvant treatment and mammography, which definitely lead to increased survival, and not for surveillance strategies of uncertain benefit.

The contradicting argumentations are not new but will lead to ever new, yet inconclusive discussions as long as there is no new evidence in the context of modern diagnostics and treatment modalities. While the lack of new evidence cannot be a persuasive excuse for indefinitely keeping old, maybe obsolete standards, it also should not lead to new surveillance strategies of hypothetical character. The global community of breast cancer care providers has the responsibility to design and perform new, much warranted trials on this subject. The Breast Commission of the German 'Arbeitsgemeinschaft Gynäkologische Onkologie' is currently designing a randomized trial comparing intensified versus conventional breast cancer surveillance. Both patients and doctors hope that this and other trials will be implemented soon and will yield new evidence. As long as results of these studies are pending, the standard, however, should remain unchanged.

\section{References}

1 Welt A, Seeber S: Program surveillance in women with early breast cancer - pro. Breast Care 2007;2: DOI: 10.1159/000111602.

2 Griggs J, Hayes D: Program surveillance after breast cancer treatment: contra. Breast Care 2007;2: DOI: 10.1159/000111697.

\begin{tabular}{|c|c|c|}
\hline KARGER & (C) 2007 S. Karger GmbH, Freiburg & $\begin{array}{l}\text { PD Dr. med. Wolfgang Janni } \\
\text { Frauenklinik Innenstadt }\end{array}$ \\
\hline $\begin{array}{l}\text { Fax +497614520714 } \\
\text { E-mail Information@Karger.de } \\
\text { www.karger.com }\end{array}$ & $\begin{array}{l}\text { Accessible online at: } \\
\text { www.karger.com/brc }\end{array}$ & $\begin{array}{l}\text { Klinikum der Ludwig-Maximilians-Universität } \\
\text { Maistr. 11, 80337 München, Germany } \\
\text { Tel. +49 89 5160-4250, Fax -4662 } \\
\text { E-mail Wolfgang.Janni@med.uni-muenchen.de }\end{array}$ \\
\hline
\end{tabular}

